\title{
Systematic Review of the Preparation Techniques of Iron Oxide Magnetic Nanoparticles
}

\author{
S. F. Hasany", I. Ahmed, Rajan J, A. Rehman \\ Faculty of Chemical and Natural Resources Engineering, Universiti Malaysia Pahang, Lebuhraya Tun Razak, 26300 Gambang, Kuantan, \\ Pahang, Malaysia
}

\begin{abstract}
Magnetism being one of the oldest scientific disciplines has been continuously studied since $6^{\text {th }}$ century BC, which still offers scientific innovations today in realm of nanomagnetism. Iron oxide nanomaterials have been growing excessive importance because of their magnetic characteristics and wide applications. Iron oxides magnetic nanoparticles with appropriate surface chemistry are prepared either by wet chemical method such as colloid chemical or sol-gel methods or by dry processes such as vapour deposition techniques. This review summarizes comparative and brief study of the methods for the preparation of iron oxide magnetic nanoparticles with a control over the size, morphology and the magnetic properties. Applications of microwave irradiation for magnetic particle synthesis are also addressed.
\end{abstract}

Keywords Iron Oxide, Nanomaterials, Preparation Methods

\section{Introduction}

Magnetic nano materials are highly pursued during the last two decades because of their improved thermo-physical properties in diverse engineering applications globally[1, 2]. This manipulation of matter, with control at nano-meter dimensions, produces new structures, materials, and devices. Nano-particles promise an unprecedented advancement in many sectors, such as medicine, energy, materials, consumer products, and manufacturing[3 - 5]. The synthesis of discrete magnetic nanoparticles with sizes ranging from 2 to $20 \mathrm{~nm}$ is of significant importance, because of their applications in multi-terabit magnetic storage devices[6]. The unique magnetic property of the nano-particles arises mainly due to the reduced sizes of isolated nano particles and contributions from inter particle interactions are negligible. Several key issues of nanoparticle synthesis are: uniformity of particle size, size control, crystal structure, shape - control and alignment for device applications[7] . Particle size dominates the magnetic behaviour of individual magnetic nanoparticles resulting in new phenol mena such as superparamagnetism, high field irreversibility, high saturation field, extra anisotropy contribu tions or shifted loops after field cooling[8]. Frenkel et al. [9] in 1930, suggested that a particle of ferromagnetic. Material, below a critical particle size $(<15 \mathrm{~nm}$ for the common materials), would consist of a single magnetic domain. Domains are the regions in which all the atomic moments point in the same direction so that within

* Corresponding author:

Pkc10003@stdmail.ump.edu.my (S. F. Hasany)

Published online at http://journal.sapub.org/nn

Copyright (C) 2012 Scientific \& Academic Publishing. All Rights Reserved each domain the magnetization is saturated, attaining its maximum possible value[10]. The magnetic behaviour of these particles above a certain temperature, i.e. the blocking temperature, is identical to that of atomic paramagnets (superparamagnetism).At blocking temperature thermal energy of particles is greater than the energy of interaction of the moments of the particles with the applied magnetic field, resulting in the fluctuation of magnetic moments of the particles about the direction of magnetic field and the moments become disordered. Thus, large susceptibilities are involved[11].

Iron oxide is found in nature in different forms. Magnetite $\left(\mathrm{Fe}_{3} \mathrm{O}_{4}\right)$, Maghemite $\left(\gamma-\mathrm{Fe}_{2} \mathrm{O}_{3}\right)$ and Hematite $\left(\alpha-\mathrm{Fe}_{2} \mathrm{O}_{3}\right)$ are the most common among them. Maghemite and Magnetite, contain single domains of about 5-20 nm in diameter. Magnetite is a common magnetic iron oxide that posses a cubic inverse spinal structure with oxygen forming an ' $\mathrm{fcc}$ ' closed packing and Fe cations occupying tetrahedral sites and octahedral sites shown in Figure 1.

Iron oxide magnetic nanoparticles differ with their atoms and bulk counter parts in their physical and chemical properties[12]. As each nanoparticle is considered a single magnetic domain, large surface area and quantum size effects lead to some dramatic change in magnetic properties resulting in super paramagnetic phenomena and quantum tunnelling of magnetization. Based on their unique physical, chemical, thermal and mechanical properties, super paramagnetic nanoparticles offer a high potential for different applications[13-17]. These applications demand nanomaterials of specific sizes, shapes, surface characteristics, and magnetic properties. Separations (HGMS), fields of highdensity data storage, ferrofluids, magnetic resonance imaging, wastewater treatment, bio separations and biomedicines, 
catalysts and electrode materials, and modified anti- corrosive coatings are some applications discussed below[18-25].

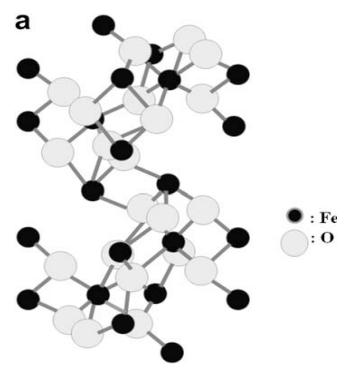

b

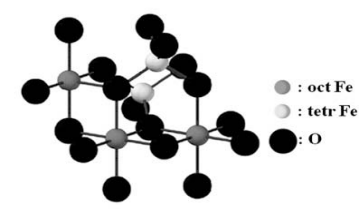

Figure 1. Crystal structures of (a) hematite and (b) magnetite

\section{Techniques for Magnetic Nanoparticles Synthesis}

Many synthesis routes have been developed to achieve proper control of particle size, polydispersity, shape, crystallinity, and the magnetic properties. Some of them are discussed below in figure 2 .

Figure.2. presents the three most important published routes or procedures for the synthesis of Iron oxide magnetic nanoparticles. Physical, chemical and biological aspects of synthesis are shown by graph. Our main focus will be chemical synthesis techniques which are better than other synthesis routes with respect to the simplicity, inexpensive and reproducibility.

\subsection{Liquid Phase Methods}

Well established and probably the simplest methods offer a better yield of magnetic nanoparticles and surface treatments[26,27].These methods allow the preparation of magnetic nano particles with a rigorous control in size and shape in a simple way. Homogeneous precipitation reactions are used to form uniform sizes i.e. the process that involves the separation of the nucleation and growth of the nuclei[28, 29].

The classical model proposed by LaMer et al.[30], in which nuclei so obtained are allowed to grow uniformly by diffusion of solutes from the solution to their surface until the final size is attained. For monodispersity achievement, nucleation should be avoided during the period of growth.

Co precipitation from aqueous solutions has been used in most of the methods, although other liquid solvents can also be used. A range of 30 to $100 \mathrm{~nm}$ Spherical magnetite particles can be obtained by the reaction of a Fe(II) salt, a base and a mild oxidant (nitrate ions) in aqueous solutions[31]. The phase and size of the particles depend on the concentration of cations, the counter ions present, and the $\mathrm{pH}$ of the solution[32].By altering the $\mathrm{pH}$ and the ionic strength, mean size of the particles can be controlled (from 15 to $2 \mathrm{~nm}$ ) [33-35].Nano particles are likely to aggregate because of large surface-area to volume ratio, to reduce their surface energy[36]. The suspension of nanoparticles can be stabilized by adding anionic surfactants as dispersing agents[37, 38]. Stabilization can also be achieved by coating the particle surfaces with proteins[39-41],starches[42,43], non-ionic detergents[37], or poly electrolytes[36]. Adsorption of such substances stabilizes the particles at electrolyte concentrations that would otherwise be high enough for coagulation to occur[44, 45].

The first controlled preparation of superparamagnetic iron oxide particles using alkaline precipitation of $\mathrm{FeCl}_{3}$ and $\mathrm{FeCl}_{2}$ was performed by Massart[46].In the original synthesis, magnetite $\left(\mathrm{Fe}_{3} \mathrm{O}_{4}\right)$ particles were roughly spherical, and their diameter measured by XRD was $8 \mathrm{~nm}$.[47] The parameters of this process were carefully studied to demonstrate the influence of the base (ammonia, $\mathrm{CH}_{3} \mathrm{NH}_{2}$, and $\mathrm{NaOH})[47,48]$ of the $\mathrm{pH}$ value, of added cations $\left[\mathrm{N}\left(\mathrm{CH}_{3}\right)_{4}{ }^{+}\right.$, $\mathrm{CH}_{3} \mathrm{NH}_{3}{ }^{+}, \mathrm{Na}^{+}, \mathrm{Li}^{+}, \mathrm{K}^{+}$, and $\left.\mathrm{NH}_{4}{ }^{+}\right]$and the $\mathrm{Fe}^{2+} / \mathrm{Fe}^{3+}$ ratio on the yield of the coprecipitation reaction and the diameter and polydispersity of the nanoparticles. When all of the separameters are modulated, it is possible to obtain particles with a size ranging from 16.6 to $4.2 \mathrm{~nm}$ [48].

\subsection{Two- Phase Methods (Microemulsion)}

The particles obtained with the co precipitation method have a broad size distribution; numerous other methods are currently being developed to produce nanoparticles with more uniform dimensions. Water-in-oil (w/o) microemulsion consisting of nano sized water droplets dispersed in an oil phase and stabilized by surfactant molecules at the water/oil interface[49-53]. The surfactant-stabilized nano cavities (typically in the range of $10 \mathrm{~nm}$ ) provide a confinement effect that limits particle nucleation, growth, and agglomeration[54]. The main advantage of the reverse micelle or emulsion technology is the diversity of nanoparticles that can be obtained by varying the nature and amount of surfactant and co-surfactant, the oil phase, or the reacting conditions.

Salazar-Alvarez[55] in Figure 2 has reported the synthesis of iron oxide nanoparticles by the use of reverse emulsions. The nanoemulsion system consisted of AOT- $\mathrm{BuOH} / \mathrm{cHex} /$ $\mathrm{H}_{2} \mathrm{O}$, with a surfactant/water molar ratio of 2.85 and a surfactant/ co surfactant molar ratio of 1 .

A sequential synthetic procedure was used to prepare the nanoparticles. One nano emulsion containing the iron source and another containing a solution of sodium hydroxide were mixed to form the magnetite nanoparticles. The nano emulsion was lysed with acetone to remove the particles from the surfactant and washed several times with ethanol. The colloidal nanoparticles exhibit super paramagnetic behaviour with high magnetization values.

The oil and water phases often contain several dissolved components, and therefore, the selection of the surfactant (and co surfactant) depends upon the physicochemical characteristics of the system. Several types of surfactants, such as cationic, anionic, or non-ionic, can be used. Difficulty in their scale-up procedures and adverse effects of residual surfactants on the properties of the particles are the main disadvantages of microemulsion method. Figure 3 is showing TEM images of nanomaterials prepared by different chemical techniques[56]. 


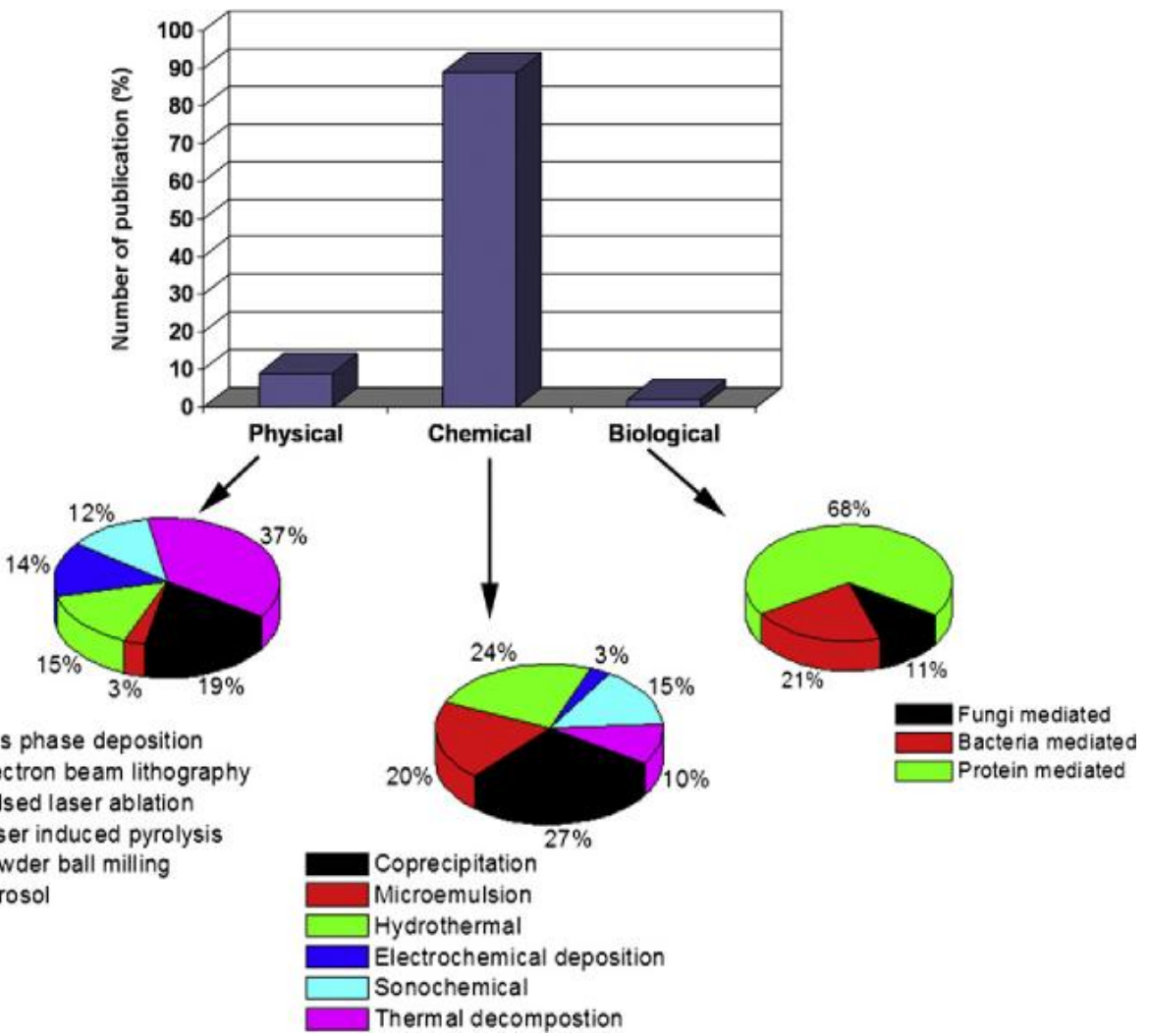

Figure 2. A comparison of published work (up to date) on the synthesis of SPIONs by three different routes. Sources: Institute of Scientific Information[5]
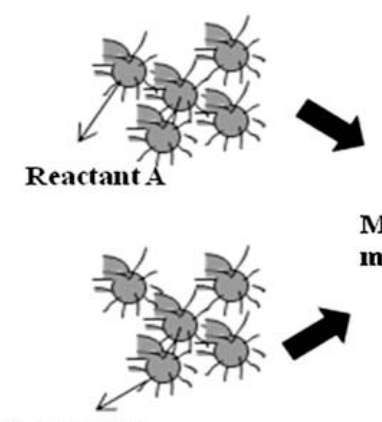

Reactant B
Mix the two microemulsions

\section{ictors} (1)

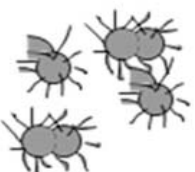
Collision and coalescence of droplets

a

\section{Chemical reaction occurs

$$
\text { \#क्ष }
$$$$
\text { 皮 }
$$

\section{AB precipitate}

forms:

Reduction reaction occurs

$$
\begin{aligned}
& \text { Metallic } \\
& \text { precipitate } \\
& \text { forms }
\end{aligned}
$$

b

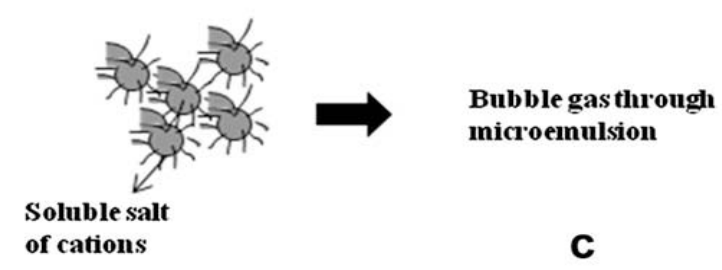

\section{Chemical reaction occurs}

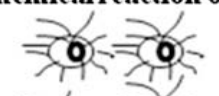

oㅏ 700

Hydroxide or oxide precipitate forms

Figure 3. Schematic representation of nanoparticle synthesis in microemulsion (a) by mixing two microemulsions (b) by adding a reducing agent, and (c) by bubbling gas through the microemulsion[55] 


\subsection{Sol-Gel Method}

The sol-gel process is a suitable wet route to the synthesis of nanostructured metal oxides[57-59]. This method is based on the hydroxylation and condensation of molecular precursors in solution, originating a "sol" of nanometric particles. The "sol" is then dried or "gelled" by solvent removal or by chemical reaction to get three-dimensional metal oxide network. Gel properties are very much dependent upon the structure created during the sol stage of the sol-gel process. The solvent used is generally water, but the precursors can also be hydrolyzed by an acid or base. Basic catalysis induces the formation of a colloidal gel, whereas acid catalysis yields a polymeric form of the gel[60]. These reactions are performed at room temperature; further heat treatments are needed to acquire the final crystalline state[61,62]. Figure 5 is showing a reaction mechanism of magnetite formation by sol-gel technique.
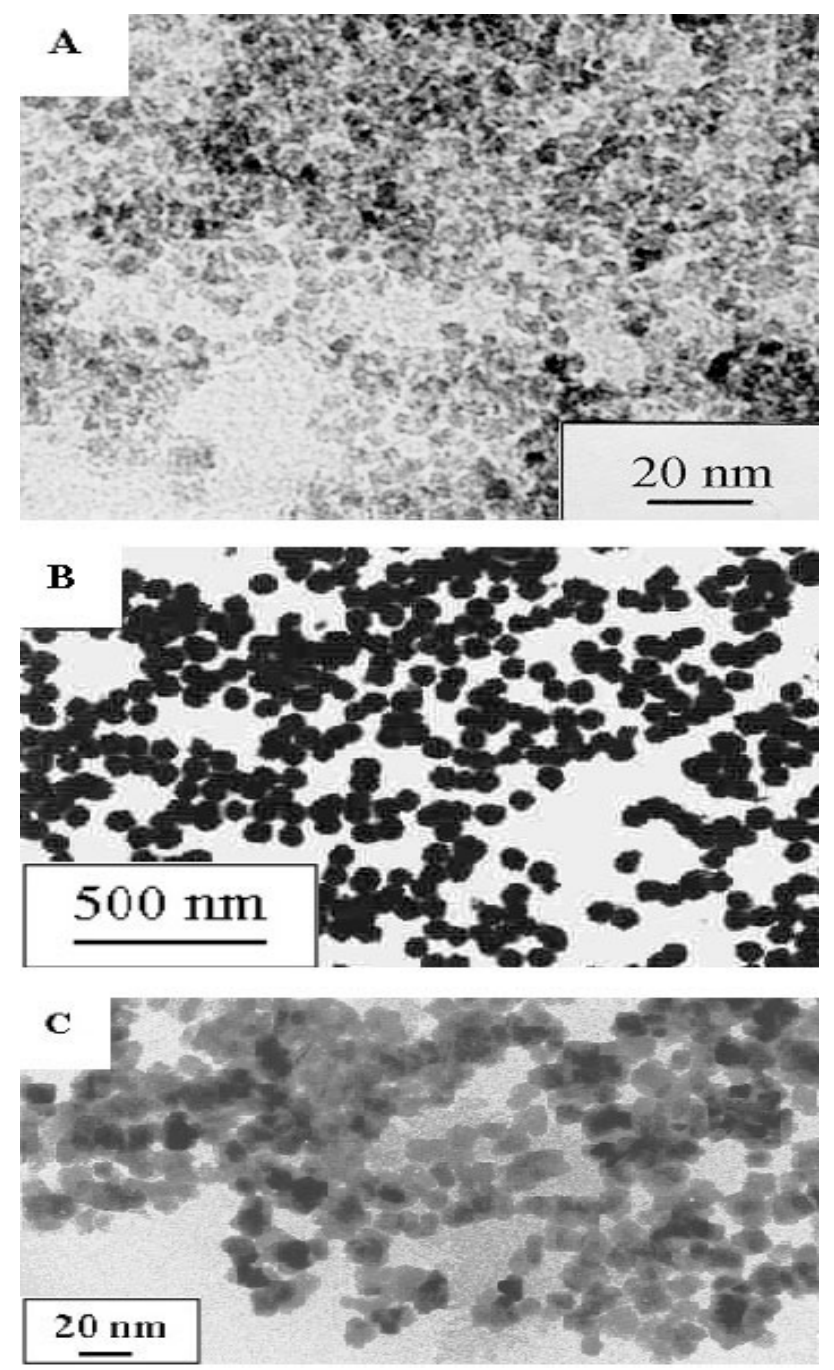

Figure 4. Magnetic nanoparticles prepared in solution by: (a) Coprecipitation (maghemite). (b) Polyol process (Fe-based alloy). (c) Microemulsions (maghemite)[56]

Parameters that influence the kinetics, growth reactions, hydrolysis, condensation reactions, and consequently, the structure and properties of the gel are solvent, temperature, nature, concentration of the salt precursors employed, $\mathrm{pH}$, and agitation.[63-66]. Magnetic ordering in the sol-gel system depends on the phases formed and the particle volume fraction, and is very sensitive to the size distribution and dispersion of the particles[67]. This method offers some advantages, such as (i) the possibility to obtain materials with a predetermined structure according to experimental conditions, (ii) the possibility to obtain pure amorphous phases, monodispersity, and good control of the particle size, (iii) the control of the microstructure and the homogeneity of the reaction products, and (iv) the possibility to embed molecules, which maintain their stability and properties within the sol-gel matrix[68].

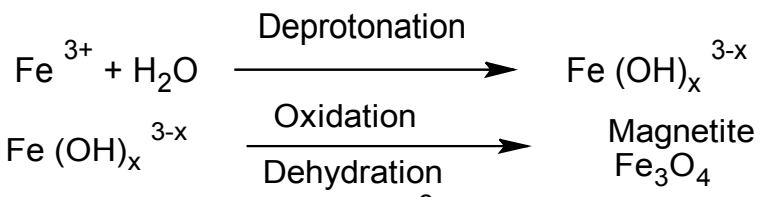

$$
\begin{aligned}
& \text { pH } 9.0,60^{\circ} \mathrm{C}
\end{aligned}
$$

Figure 5. Scheme showing the reaction mechanism of magnetite particle formation from an aqueous iron (III) solution by addition of a base

Iron oxide-silica aero -gel composites have been prepared by the sol-gel method[69-71] and found to be 2-3 orders of magnitude more reactive than conventional iron oxide. The increase in reactivity was attributed to the large surface area of iron oxide nanoparticles supported on the silica aero-gel[72, 73]. Commercial precursors (TEOS and Fe (III) solutions) were dissolved in an alcoholic aqueous medium, and the gels formed after a few days were heated to produce the final materials[74-76].

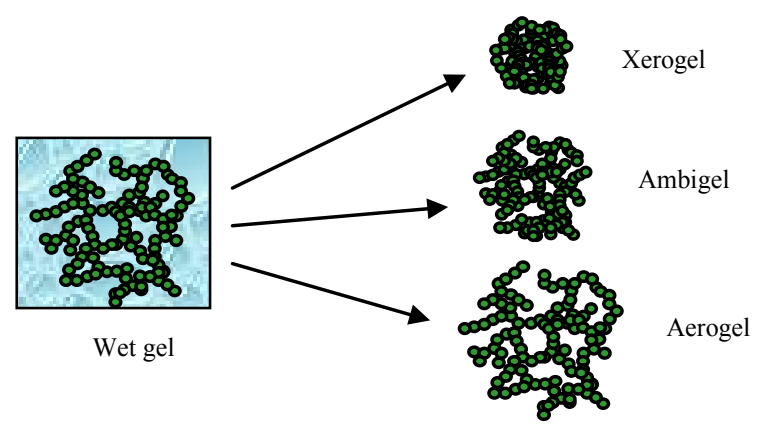

Figure 6. Hydrolysis and condensation of molecular precursors result in a wet gel, composed of a three-dimensional network of manometer-scale oxide particles surrounding an interconnected network of pores that are filled with fluid, typically the solvent. Allowing the pore fluid to evaporate under ambient pressure leads to pore collapse and a highly densified xerogel. Exchange of the pore fluid with a low polarity solvent followed by evaporation leads to minimal pore collapse and an ambigel that retains $80-90 \%$ of the porosity of the wet gel. Exchange of the pore fluid with liquid $\mathrm{CO}_{2}$ followed by supercritical drying leads to an ultra high porosity and low density material known as an aerogel

Erin Camponeschi et al. studied sol-gel processing method by the addition of common surfactant i.e. Sodium benzene sulfonate (NaDDBS), resulted in the decrease of the free energy system and allowed the creation of stable nano sized iron oxide particles without generating a $3 \mathrm{D}$ gel network[77]. The $\mathrm{Fe}\left(\mathrm{NO}_{3}\right)_{3} \cdot 9 \mathrm{H}_{2} \mathrm{O}$ and $\mathrm{FeCl}_{3} \cdot 6 \mathrm{H}_{2} \mathrm{O}$ precursors gave rise to a gel with nano sized primary particles, 
according to the classic sol-gel process. NaDDBS addition prior to gelation, affected the particle size of the resulting iron oxide particles. The $\mathrm{Fe}\left(\mathrm{NO}_{3}\right)_{3} \cdot 9 \mathrm{H}_{2} \mathrm{O}$ did not form a gel in the presences of the NaDDBS, but still able to the formation of nano sized particles, similar to the nano scale particles formed the gel counterpart.

Sol-gel synthesis provides an extremely easy method of creating a large variety of metal oxides from their metal salts at ambient conditions and at low temperatures. Sol-Gel methods include contamination from by-products of reactions, as well as the need for post-treatment of the products. The drawback of the method is that it generates 3D oxide networks, and hence, it is limited in its efficiency regarding the formation of independent, disconnected nano sized particles.

\subsection{Gas/ Aerosol - Phase Methods}

Spray and laser pyrolysis have been shown to be excellent techniques for the direct and continuous high rate production of well-defined magnetic nanoparticles under exhaustive control of the experimental conditions[78].

In spray pyrolysis, a solution of ferric salts and a reducing agent in organic solvent is sprayed into a series of reactors; where the aerosol solute condenses and the solvent evaporates[79].The resulting dried residue consists of particles whose size depends upon the initial size of the original droplets. Maghemite particles with size ranging from 5 to 60 $\mathrm{nm}$ with different shapes have been obtained using different iron precursor salts in alcoholic solution[80].

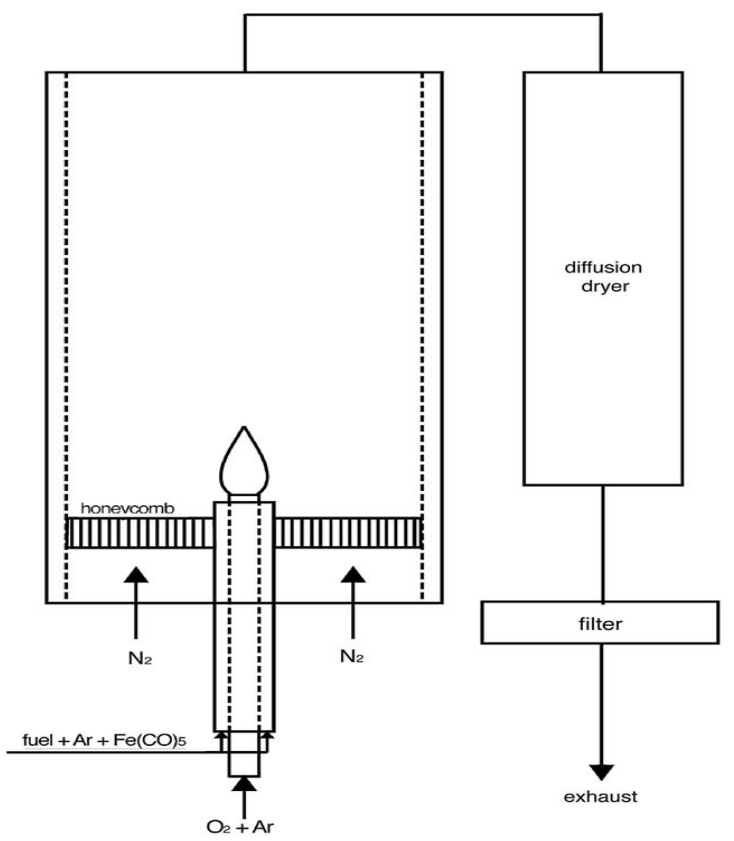

Figure 7. Experimental setup for flame synthesis of iron oxide nanoparticles[88]

Laser pyrolysis of organometallic precursors[81-84] is based on the resonant interaction between laser photons and at least one gaseous species, reactant or sensitizer. A sensitizer is an energy transfer agent that is excited by absorption of $\mathrm{CO}_{2}$ laser radiation and transfers the absorbed energy to the reactants by collision[85]. The method involves heating a flowing mixture of gases with a continuous wave $\mathrm{CO}_{2}$ laser to initiate and sustain a chemical reaction until a critical concentration of nuclei is reached in the reaction zone, and homogeneous nucleation of particles occurs[86]. The nucleated particles formed during the reaction are entrained by the gas stream and are collected at the exit[87]. Benjamin and Kozo[88] studied the synthesis of Iron oxide by using gas-phase, laminar diffusion flame process for the synthesis of reduced iron oxide nanoparticles shown in figure 6 .

Gas /Aerosol phase methods yield high quality products but the percentage yield is usually low enough, Variables such as oxygen concentration, gas phase impurities, and the heating time must be controlled precisely to obtain pure products. The equipments used in these methods are also expensive.

\subsection{Polyols Method}

A very promising technique for the preparation of well-defined shapes and size controlled nanoparticles that could be used in biomedical applications [89].By controlling the kinetic of the precipitation, non agglomerated metal particles with well-defined shape and size can be obtained. A better control of the average size of the metal particles can be obtained by seeding the reactive medium with foreign particles (heterogeneous nucleation). In this way, nucleation and growth steps can be completely separated and uniform particles result. Iron particles around $100 \mathrm{~nm}$ can be obtained by dis-proportionation of ferrous hydroxide in organic media[90].

The solvents as polyols for example, polyethylene glycol, offer interesting properties: owing to their high dielectric constants, they act as solvents able to dissolve inorganic compounds, and owing to their relatively high boiling points, they offer a wide operating-temperature range (from $25^{\circ} \mathrm{C}$ to the boiling point) for preparing inorganic compounds[91]. Polyols also serve as reducing agents as well as stabilizers to control particle growth and prevent inter particle aggregation.

Joseyphus et al.[92] evaluated several factors governing the production yield of Fe particles like type of polyols, ferrous salts, ferrous ion concentration, hydroxyl ion concentration, and reaction temperature. He found out the yield and size of Fe particles varied depending upon the reduction potential of the polyols.

Hong-Ling Liua[93] studied the one pot polyols synthesis of iron oxides with sizes sub-5 nm as shown in figure 7 .

TEM images of two samples obtained by reacting $\mathrm{Fe}(\mathrm{acac})_{3}$ with 1,2-hexadecanediol in the presence of the PVP polymer surfactant in octyl ether. The nanoparticles from the two samples are well distinct as individual entities, with little aggregation. Both of them show tight size distributions and Samples I and II have an average dimension of 4 and $5 \mathrm{~nm}$, respectively, which are comparable to the estimations by Scherrer's formula[94].

By inspecting single nanoparticles by HRTEM, as shown in figure Y(c) for Sample I, displays distinct lattices of $\{220\}$ 
faces, representing the (lllll 111 ) projection of the highly crystalline magnetite structure[95,96].The nanoparticle is almost encompassed by the circle, which defines the boundary between the bulk and the surface. Inside, the arrangement of the motifs is crystallographically positioned, while disorder can be detected outside. The image also reveals the coating layer of the polymer molecules on the nanoparticle surface.
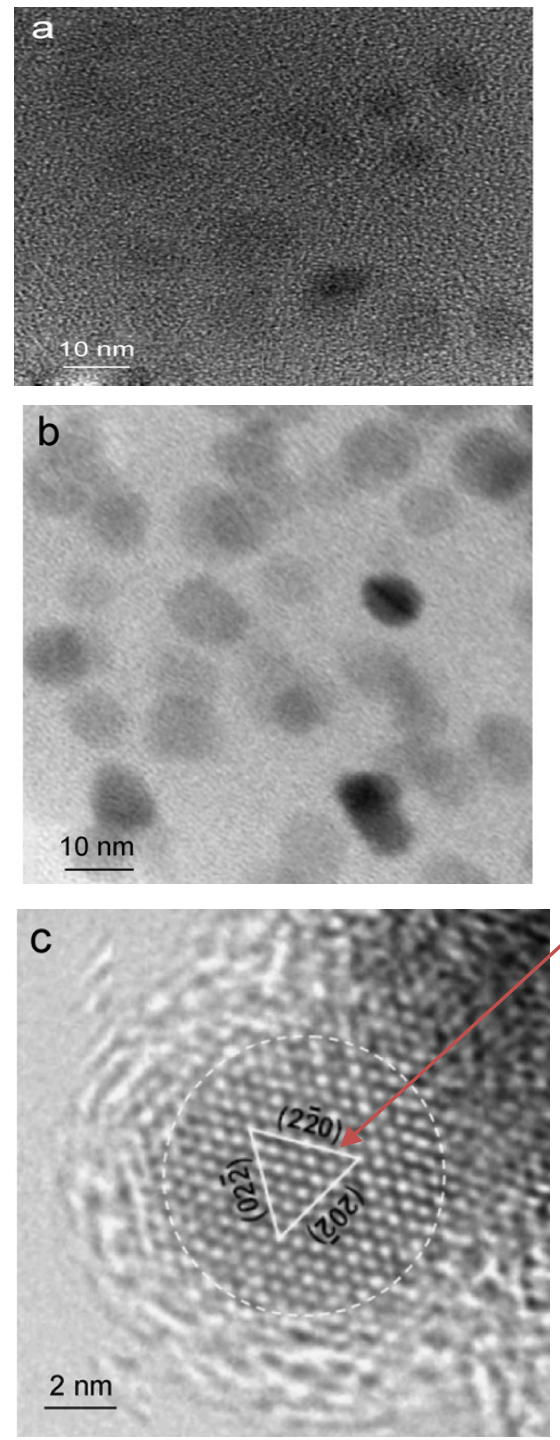

Figure 8. TEM images (a) sample I and (b) Sample II with (c) HRTEM of a single magnetite nanoparticle[93]

\subsection{Hydrothermal Reaction Methods}

These reactions are performed in aqueous media in reactors or autoclaves where the pressure can be higher than 2000 psi and the temperature can be above $200^{\circ} \mathrm{C}$. Hydrothermal methods rely on the ability of water to hydrolyze and dehydrate metal salts on elevated conditions, and the very low solubility of the resulting metal oxides in water at these conditions to generate supersaturation[97]. Hao and Teja,[98] conducted a detailed investigation of the effects of precursor concentration, temperature, and residence time on particle size and morphology in this method.

The particle size and size distribution increased with precursor concentration. However, the residence time had a more significant impact on the average particle size than feed concentration. Monodispersed particles were produced at short residence times[99,100].Figure 8 showing schematic presentation of experiments.

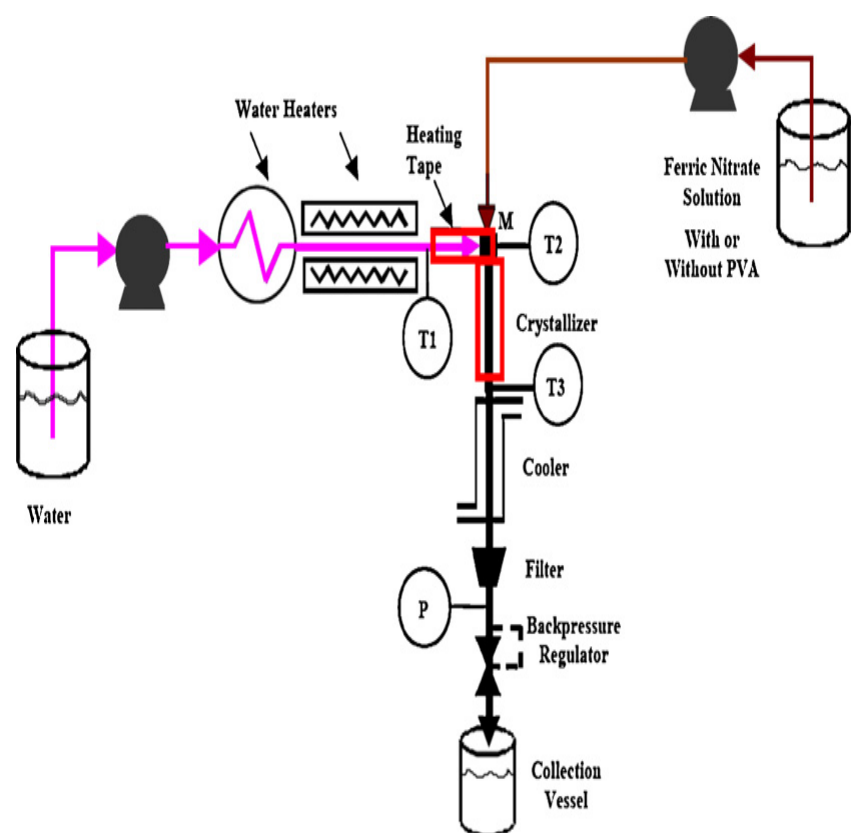

Figure 9. Schematic diagram of the apparatus used by Teja for hudrothermal method[99]

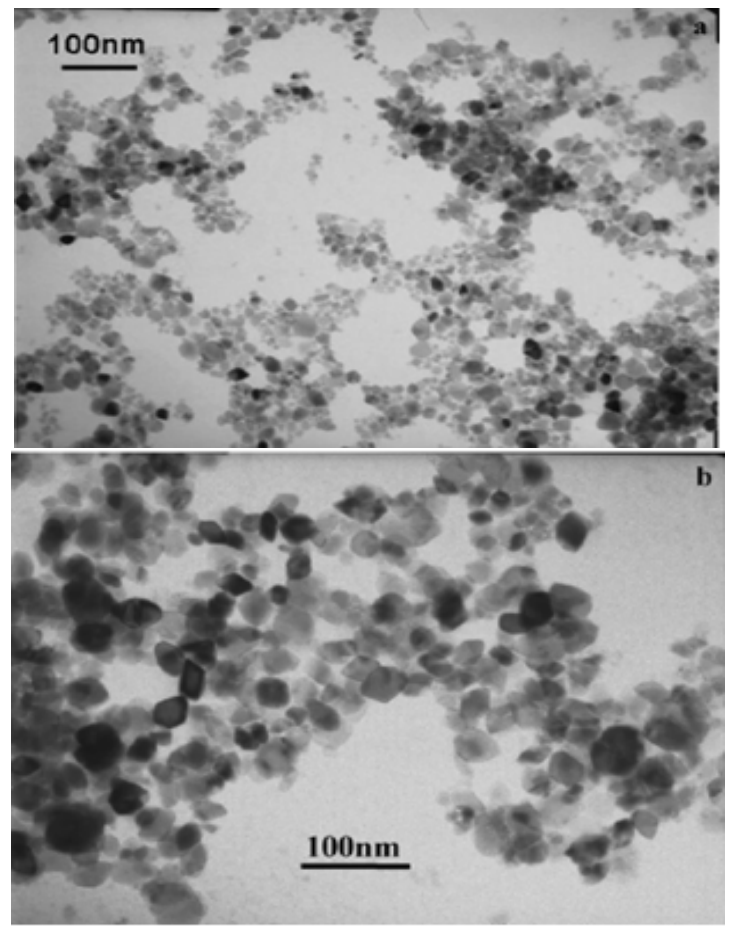

Figure 10. TEM images of iron oxide nanoparticles obtained in (a) experiment S1(100,000X) and (b) experiment S2 (140,000X)[99]

The effect of changing the precursor (ferric nitrate) concentration from 0.03 to $0.06 \mathrm{M}$ (with all other variables kept constant) is studied in Figure 9, which shows TEM images of particles obtained in experiments $\mathrm{S} 1$ and $\mathrm{S} 2$. In experiment $\mathrm{S} 1$, the precursor concentration was $0.03 \mathrm{M}$ and 
small, spherical particles with an average particle radius of $15.6 \pm 4.0 \mathrm{~nm}$ were obtained. A few larger rhombic particles were also obtained. In experiment S2, the ferric nitrate concentration increased to $0.06 \mathrm{M}$, and average particle size increased to $27.4 \pm 7.0 \mathrm{~nm}$. However, the particles were now mostly rhombic, and there were few, if any, smaller spherical particles.

\section{Sonolysis}

Iron oxide can be prepared by the decomposition Sonolysis of organometallic precursors. Polymers, organic capping agents, or structural hosts are used to limit the nanoparticle growth[101,102].Figure 10, is representing general steps of iron oxide synthesis by Sonolysis technique.

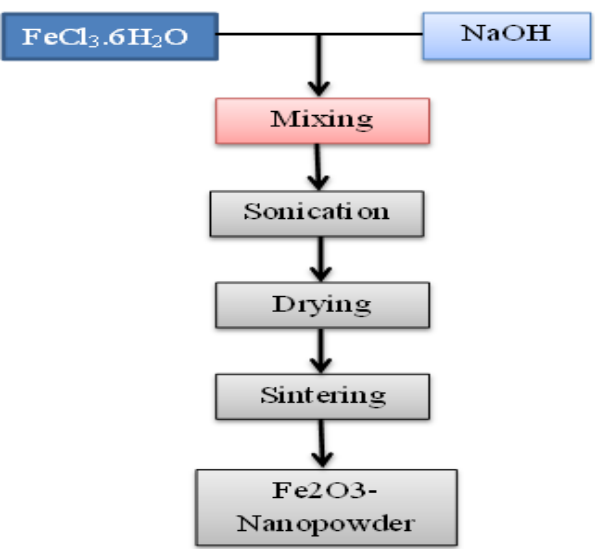

Figure 11. Flow chart of sonochemical synthesis of iron oxide[103]
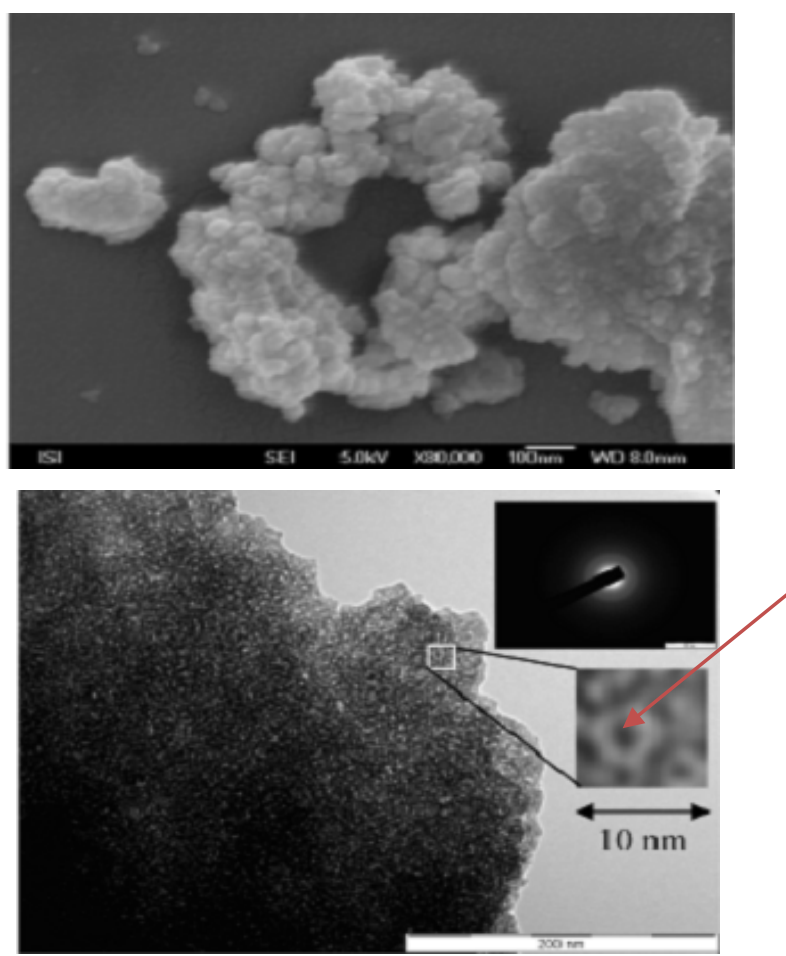

Figure 12. (a) SEM image of sonochemically prepared $\mathrm{Y}-\mathrm{Fe}-\mathrm{O}$ displaying aggregates of nanoparticles. (b) TEM image and corresponding SAED pattern showing that aggregates are composed of approximately $3 \mathrm{~nm}$ sized particles having the amorphous nature[109]
Ultrasonic irradiation caused cavitations in an aqueous medium where the formation, growth and collapse of micro bubbles occurred $[103,104]$.Cavitation can generate a temperature of around $5000{ }^{\circ} \mathrm{C}$ and a pressure of over $1800 \mathrm{KPa}$, which enable many unusual chemical reactions to occur[105, 106]. In many cases thermally induced processes provide crystalline nanoparticles. In contrast, ultrasonic-driven reactions yield amorphous materials that are produced in collapsing cavitations bubble as enormous cooling rates (1010 $\mathrm{K} / \mathrm{s}$ ) prevent their crystallization during quenching, thus calling for heat-treatment after synthesis[107,108].

Jiri Pinkas et al.[109] studied the sonochemical synthesis of yttrium iron oxide nanoparticles embedded in Acetate Matrix, resulting in approximately $3 \mathrm{~nm}$ sized particles as shown in figure 11. On the basis of the SEM and TEM images, it was proposed that the globular agglomerates formed by the sonochemical process are composed of ultra small nanoparticles of corresponding amorphous iron yttrium oxide that are embedded in an acetate matrix. The simple control of the Stoichiometry was achieved by the starting molar ratio of the $\mathrm{Y}$ and $\mathrm{Fe}$ precursors.

\section{Microwave Irradiation}

Microwave chemistry has received great attention in recent years, as its use has been started in preparative chemistry and material synthesis since $1986[110,111]$.

The greatest advantage of microwave irradiation is that it can heat a substance uniformly through a glass or plastic reaction container, leading to a more homogeneous nucleation and a shorter crystallization time compared with those for conventional heating. This is beneficial to the formation of uniform colloidal materials. Norihito Kijima reported synthesizing ultrafine $\alpha-\mathrm{Fe}_{2} \mathrm{O}_{3}$ nanoparticles with an extremely narrow distribution by microwave heating. As compared with other previously reported iron oxides, ultrafine $\alpha-\mathrm{Fe}_{2} \mathrm{O}_{3}$ nanoparticles a significantly high electrochemical performance because of their uniformity and size[112].

Figure 12 displays the TEM images of the $\alpha-\mathrm{Fe}_{2} \mathrm{O}_{3}$ nanoparticles. Most primary particles had ellipsoid shapes, and these primary particles connected to each other. Agglomerations would occur when the TEM. The average diameter of the primary particles was less than $10 \mathrm{~nm}$. The electron diffraction pattern and fringes in some particles showed that these nanoparticles were single crystals.J.G. Parsons et al.[113] studied the microwave-assisted synthesis of iron oxide/oxyhydroxide nanoparticles by using a standard microwave oven, and high concentrations of the starting materials. The nanoparticles formed from the slow titration of $\mathrm{FeCl}_{3}$ with sodium hydroxide have controlled growth and controlled crystal structure dependent on the temperature of the synthesis. As shown in figure 13. It was also investigated that the nanoparticles synthesized using this techniques have similar growth on three different axes of the crystal structure as the anisotropy in the crystals is low indicating that the 
nanoparticles are spherical in nature, as shown by TEM in Figure 14.
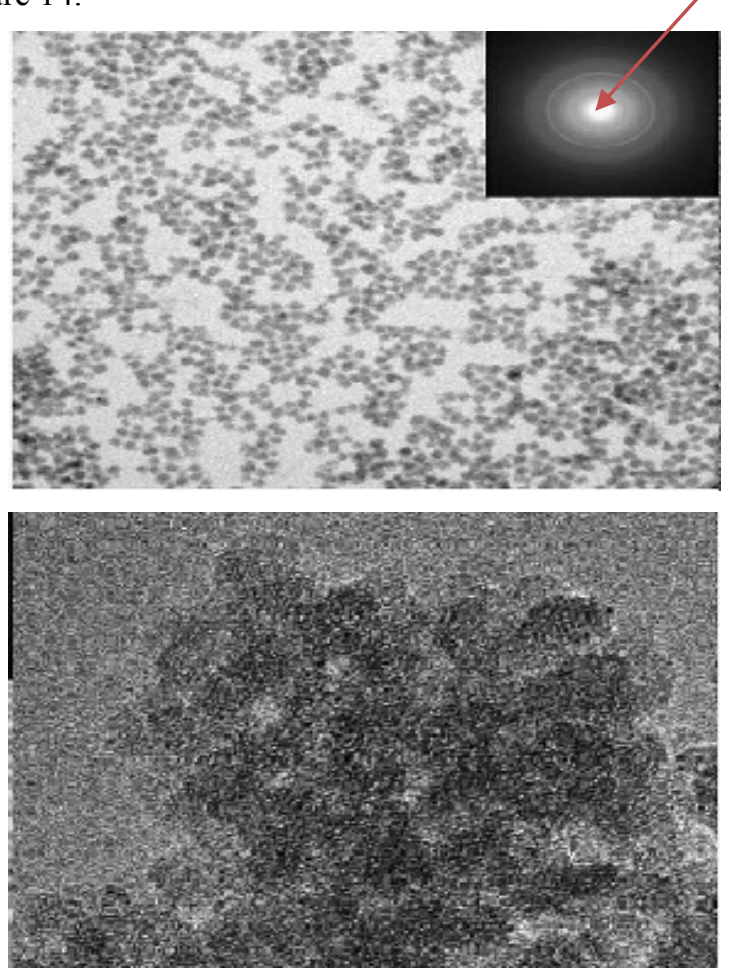

Figure 13. TEM images of the $\alpha-\mathrm{Fe}_{2} \mathrm{O}_{3}$ nanoparticles generated by microwave irradiation[112]

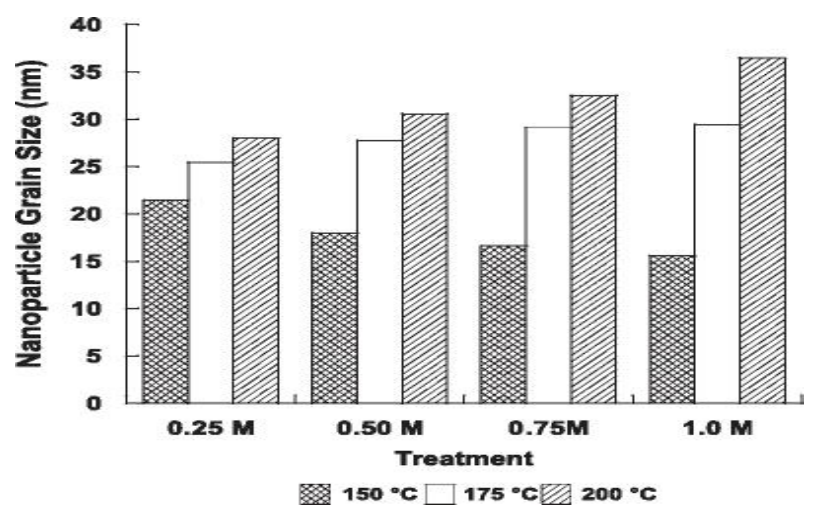

Figure 14. Size of nanoparticles formed at $150-250^{\circ} \mathrm{C}$ varying the initial iron (III) chloride concentrations using microwave-assisted synthesis for 30 $\min$ reaction time[113]

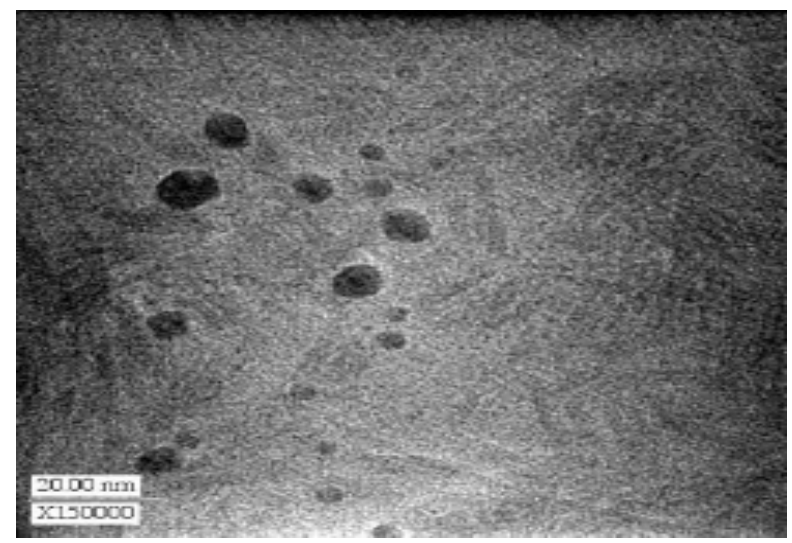

Figure 15. TEM micrograph of iron oxide nanoparticles synthesized at $100{ }^{\circ} \mathrm{C}$, with $30 \mathrm{~min}$ of pulsed microwave irradiation[113]

\section{Conclusions and Perspectives}

The major focus of current research on Iron oxide magnetic nanoparticles synthesis is finding new methods or improving the conventional ones in order to obtain reliable/reproducible superparamagnetic nanoparticles with optimum surface charge, shape, size, colloidal stability in a biological environment, biocompatibility and saturation magnetization. The synthesis of magnetic nanoparticles, covering a wide range of compositions and tuneable sizes, has made substantial progress, especially over the past decade. Different kinds of mono-disperse spherical nano crystals with controllable particle sizes and compositions have been synthesized by a wide range of chemical synthetic procedures: co precipitation, microemulsion, sol-gel reactions, aerosol methods hydrothermal decomposition of metal-surfactant complexes, polyols processes and sonolysis. A new method has also been reported i.e. microwave synthesis (MW). Rapid heating is one of the key features of microwave heating. Microwave irradiation synthesis is getting importance in other fields of research as well because this method is environmental friendly and a domestic microwave can be used for research purpose as well. Future studies should also aim to address different challenges faced in iron oxide magnetic nanoparticles synthesis and applications. A major challenge for all methods is the design of magnetic nanoparticles with effective surface coatings that provide optimum performance in vitro and in vivo biological applications. Additional challenges include scale-up, toxicity, and safety of large-scale particle production cost and processes.

\section{ACKNOWLEDGEMENTS}

S.F. Hasany is grateful to CGS, University Malaysia Pahang for financial assistance.

\section{REFERENCES}

[1] (a) A. P. Alivisatos, Science, 1996, 271, 933; (b) H. Weller, Angew.Chem., Int. Ed. Engl., 1993, 32, 41; (c) Clusters and Colloids, ed. G. Schmid, VCH Press, New York, 1994; (d) Nanoscale Materials in Chemistry, ed. K. J. Klabunde, Wiley-Interscience, New York, 2001; (e) Nanoparticles and Nanostructured Films, ed. J. H. Fendler, Wiley- VCH, Weinheim, 1998).

[2] Morteza Mahmoudi, Shilpa Sant, Ben Wang, Sophie Laurent, Tapas Sen. Advanced Drug Delivery Reviews (6)3 (2011) 24-46.

[3] A. Tari, R.W. Chantrell, S.W. Charles, J. Popplewell. Physica B \& C 97 (1) (1979) 57-64.

[4] P. Poizot, S. Laruelle, S. Grugeon, L. Dupont, J.M. Tarascon. Nature 407 (6803) (2000) 496-499.

[5] M. Mahmoudi, A. Simchi, M. Imani, P. Stroeve, A. Sohra- 
bi.Thin Solid Films 518 (15) (2010) 4281-4289.

[6] (a) D. D. Awschalom and D. P. DiVicenzo, Phys. Today, 1995, 4, 43; (b) K. Raj and R. Moskowitz, J. Magn. Magn. Mater. 1990, 85, 233; (c) I.M. L. Billas, A. Chatelain and W. A. de Heer, Science, 1994, 265, 1682; (d) R. C. O’Handley, Modern Magnetic Materials, Wiley, New York,1999).

[7] Rudolf Hergt, Silvio Dutz, Robert M"uller and Matthias Zeisberge. Chemcomm.rsc.org December 2002.

[8] Batlle X and Labarta A 2002 J. Phys. D: Apply. Phys. 35 R15.

[9] Frenkel J and Dorfman J 1930 Nature 126- 274.

[10] The Physics and Chemistry of Nanosolids Wiley. FrankJ.Owens, Charles P.PooleJr.2009.

[11] Bean C P and Livingston J D 1959 J. Appl. Phys. 30120.

[12] Babes L, Denizot B, Tanguy G, Le Jeune JJ, Jallet P.a parametricstudy. J Coll Int Sci 1999)(212) 474-82.

[13] Goya GF, Berquo TS, Fonseca FC. J ApplPhys 2003;94(5):3520-8.

[14] Arbab AS, Bashaw LA, Miller BR, Jordan EK, Lewis BK, Kalish H, Frank JA. Radiology 2003;229 (3):838-46.

[15] Reimer P, Weissleder R. Radiology 1996;36:153-63.

[16] Pankhurst QA, Connolly J, Jones SK, Dobson J. J Phys D: Appl Phys 2003;36:R167-81.

[17] Ha“ feli U, Schu“ tt W, Teller J, Zborowski M. New York:Plenum Press; 1997.

[18] Dong-Hwang Chen*, Shih-Hung Huang. Process Biochemistry 39 (2004) 2207-2211.

[19] Suber L, Foglia S, Ingo GM, Boukos N. Organomet Chem 2001;15:414-20.

[20] Šafa r'́1k I. Water Res 1995;29:101-5.

[21] Šafa rr'1k I, Šafa'r' 1ková M. Water Res 2002;36:196-200.

[22] Denizli A, Say R. J Biomater Sci Polym Edn 2001;12:1059-73.

[23] Schütt W, Grüttner C, Häfeli U, Zborowski M, Teller J, Putzar H, et al.a mini-review. Hybridoma 1997;16:109-17.

[24] Häfeli U, Schütt W, Teller J, Zborowski M. New York: Plenum Press, 1997.

[25] Xu Z, Liu Q, Finch JA. New York: Marcel Dekker, 1999. p. $31-50$.

[26] Ying-Sing Li a, Jeffrey S. Church, Andrea L. Woodhead, Filsun Moussa . Spectrochimica Acta Part A 76 (2010) 484-489.

[27] P. Majewski, B. Thierry, Critical Reviews in Solid State and Material Sciences 32 (3-4) (2007) 203-215.

[28] Sugimoto T 2000 Fine Particles: Synthesis, Characterisation and Mechanism of Growth (New York: Marcel Dekker)

[29] Bing Tanga, Liangjun Yuana, Taihong Shib, Linfeng Yua, Youchun Zhua. Journal of Hazardous Materials 163 (2009) $1173-1178$

[30] LaMer V K and Dinegar R H 1950 J. Am. Chem. Soc. 72
4847.

[31] T. Sugimoto, E. Matijevic, Journal of Colloid and Interface Science 74 (1) (1980) 227-243.

[32] A. Chastellain, A. Petri, H. Hofmann, Journal of Colloid and Interface Science 278 (2) (2004) 353-360.

[33] Jolivet J P 2000 Metal Oxide Chemistry and Synthesis: From Solutions to Solid State (New York: Wiley)

[34] P. Tartaj, M.D. Morales, S. Veintemillas-Verdaguer, T. Gonzalez-Carreno, C.J. Serna, Journal of Physics D:Applied Physics 36 (13) (2003) R182-R197.

[35] P. Tartaj, M.P. Morales, T. Gonzalez-Carreno, S. Veintemillas-Verdaguer, C.J. Serna, Journal of Magnetism and Magnetic Materials 290 (2005) 28-34.

[36] D.K. Kim, Y. Zhang, W. Voit, K.V. Rao, M. Muhammed, Journal of Magnetism and Magnetic Materials 225 (1-2) (2001) 30e36.

[37] D.K. Kim, M. Mikhaylova, Y. Zhang, M. Muhammed, Chemistry of Materials 15 (8) (2003) 1617-1627.

[38] C.L. Lin, C.F. Lee, W.Y. Chiu, Journal of Colloid and Interface Science 291 (2) (2005) 411-420.

[39] Z.P. Xu, Q.H. Zeng, G.Q. Lu, A.B. Yu, Chemical Engineering Science 61 (3) (2006) 1027-1040.

[40] H. Lee, E. Lee, D.K. Kim, N.K. Jang, Y.Y. Jeong, S. Jon, Journal of the American Chemical Society 128 (22) (2006) 7383-7389.

[41] S. Mohapatra, N. Pramanik, S. Mukherjee, S.K. Ghosh, P. Pramanik, Journal of Materials Science 42 (17) (2007) 7566-7574.

[42] D.K. Kim, M. Mikhaylova, F.H. Wang, J. Kehr, B. Bjelke, Y. Zhang, T. Tsakalakos, M. Muhammed, Chemistry of Materials 15 (23) (2003) 4343-4351.

[43] Bergemann C, M"uller-Schulte D, Oster J, Brassard L and L"ubbe A S 1999 J. Magn. Magn. Mater. (194)(45).

[44] R.M. Cornell, U. Schwertmann, The Iron Oxides: Structure, Properties, Reactions, Occurrences and Uses, second ed. Wiley-VCH, Weinheim, 2003.

[45] Sophie Laurent,Delphine Forge, Marc Port,Alain Roch, Caroline Robic, Luce Vander Elst, † and Robert N. Muller. Chem. Rev. 2008, 108, 2064-2110.

[46] Massart, R. IEEE Trans. Magn. 1981, 17, 1247.

[47] Massart, R.; Cabuil, V. J. Chim. Phys. 1987, 84, 7.

[48] Gribanow, N. M.; Bibik, E. E.; Buzunov, O. V.; Naumov, V. N. J. Magn. Magn. Mater 1990, 85, 7.

[49] A. Tavakoli, M. Sohrabi, A. Kargari, Chemical Papers (2007) 61 (3) $151-170$.

[50] Y.X. Pang, X.J. Bao, Journal of Materials Chemistry 12 (12) (2002) 3699-3704.

[51] V. Pillai, P. Kumar, M.J. Hou, P. Ayyub, D.O. Shah, Advances in Colloid and Interface Science 55 (1995)241-269.

[52] P. Tartaj, L.C. De Jonghe, Journal of Materials Chemistry 10 (12) (2000) 2786-2790. 
[53] I. Capek, Advances in Colloid and Interface Science 110 (1-2) (2004) 49-74.

[54] Pileni M P 1993 J. Phys. Chem. (97) (6961).

[55] Salazar-Alvarez, G. Doctoral Thesis, Stockholm, Sweden, 2004.

[56] Pedro Tartaj1, Mar'ia del Puerto Morales1,Sabino Veintemillas-Verdaguer, Teresita Gonz'alez-Carre no and Carlos J Serna (2003). J. Phys. D: Appl. Phys. 36 R182-R197

[57] Dai, Z.; Meiser, F.; Mo"hwald, H. J. Colloid Interface Sci. 2005, 28 (1), 298.

[58] Durães, L.; Costa, B. F. O.; Vasques, J.; Campos, J.; Portugal, A. Mater. Lett. 2005, 59 (7) 859.

[59] Ismail, A. A. Appl. Catal., B 2005, 58, 115.

[60] U.T. Lam, R. Mammucari, K. Suzuki, N.R. Foster, Industrial \& Engineering Chemistry Research 47 (3) (2008) 599-614.

[61] Liu, X. Q.; Tao, S. W.; Shen, Y. S. Sens. Actuators, A 1997. 40,161 .

[62] Kojima, K.; Miyazaki, M.; Mizukami, F.; Maeda, K. J. Sol-Gel Sci. Technol. 1997, 8, 77.

[63] Cannas, C.; Gatteschi, D.; Musinu, A.; Piccaluga, G.; Sangregorio, C. J. Phys. Chem. 1998, 102, 7721.

[64] Ennas, G.; Musinu, A.; Piccaluga, G.; Zedda, D.; Gatteschi, D.; Sangregorio, C.; Stanger, J. L.; Concas, G.; Spano, G. Chem. Mater. 1998, 10, 495.

[65] Brinker, C. J.; Sherrer, G. W. Sol-Gel Science; Academic Press: New York, 1990.

[66] da Costa, G. M.; De Grave, E.; de Bakker, P. M. A.; Vandeberghe, R. E. J. Solid State Chem. 1994, 113, 405.

[67] A. Tavakoli, M. Sohrabi, A. Kargari, Chemical Papers 61 (3) (2007) 151-170.

[68] Raileanu, M.; Crisan, M.; Petrache, C.; Crisan, D.; Jitianu, A.; Zaharescu, M.; Predoi, D.; Kuncser, V.; Filoti, G. Rom. J. Phys. 2005, 50 (5-6), 595 .

[69] M. Tadic, D. Markovic, V. Spasojevic, V. Kusigerski, M. Remskar, J. Pirnat, Z. Jaglicic, Journal of Alloys and Compounds 441 (1-2) (2007) 291-296.

[70] Z.Z. Xu, C.C. Wang, W.L. Yang, S.K. Fu, Journal of Materials Science 40 (17) (2005) 4667- 4669.

[71] Y.H. Deng, C.C. Wang, J.H. Hu, W.L. Yang, S.K. Fu, Colloids and Surfaces A: Physicochemical and Engineering Aspects $262(1-3)(2005) 87-93$.

[72] C.T. Wang, R.J. Willey, Journal of Non-Crystalline Solids 225 (1) (1998) 173-177.

[73] C.-T. Wang, S.-H. Ro, Applied Catalysis A: General 285 (1e2) (2005) 196-204.

[74] A. Tavakoli, M. Sohrabi, A. Kargari, Chemical Papers 61 (3) (2007) 151-170.

[75] G. Ennas, A. Musinu, G. Piccaluga, D. Zedda, D. Gatteschi, C. Sangregorio, J.L. Stanger, G. Concas, G. Spano,Chemistry of Materials 10 (2) (1998) 495-502.

[76] S. Bruni, F. Cariati, M. Casu, A. Lai, A. Musinu, G. Piccaluga,
S. Solinas, Nanostructured Materials 11 (5) (1999) 573-586.

[77] Erin Camponeschi, Jeremy Walker, Hamid Garmestani. ACS Symposium Series; American Chemical Society: Washington, DC, 2008.

[78] Pecharroman, C.; Gonzalez-Carreno, T.; Iglesias, J. E. Phys. Chem.Miner. 1995, 22, 21.

[79] Gonzalez-Carreno, T.; Morales, M. P.; Gracia, M.; Serna, C. J. Mater. Lett. 1993, 18, 151.

[80] A. Tavakoli, M. Sohrabi, A. Kargari, Chemical Papers 61 (3) (2007) 151-170.

[81] S. Martelli, A. Mancini, R. Giorgi, R. Alexandrescu, S. Cojocaru, A. Crunteanu, I. Voicu, M. Balu, I. Morjan, Applied Surface Science 154-155 (2000) 353-359.

[82] R. Alexandrescu, I. Morjann, A. Crunteanu, S. Cojocaru, S. Petcu, V. Teodorescu, F. Huisken, B. Koh, M. Ehbrecht, Materials Chemistry and Physics 55 (2) (1998) 115-121.

[83] I. Morjan, R. Alexandrescu, I. Soare, F. Dumitrache, I. Sandu, I. Voicu, A. Crunteanu, E. Vasile, V. Ciupina, S. Martelli, Materials Science and Engineering: C 23 (1e2) (2003) 211-216.

[84] F. Dumitrache, I. Morjan, R. Alexandrescu, V. Ciupina, G. Prodan, I. Voicu, C. Fleaca, L. Albu, M. Savoiu, I. Sandu, E. Popovici, I. Soare, Applied Surface Science 247 (1-4) (2005) 25-31.

[85] P. Tartaj, M.P. Morales, T. Gonzalez-Carreno, S. Veintemillas-Verdaguer, C.J. Serna, Journal of Magnetism and Magnetic Materials 290 (2005) 28-34.

[86] P. Tartaj, M.D. Morales, S. Veintemillas-Verdaguer, T. Gonzalez-Carreno, C.J. Serna, Journal of Physics D: Applied Physics 36 (13) (2003) R182-R197.

[87] Benjamin M.Kumfer, KozoShinoda , BalachandranJeyadevan , IanM.Kennedy, Journal of Aerosol Science 41(2010)257-265

[88] Christoph Schweiger, ClemensPietzonka, JohannesHeverhagen, ThomasKissel . International Journal of Pharmaceutics (2011) (Article in press).

[89] Fievet F, Lagier J P, Blin B, Beaudoin B and Figlarz M 1989. Solid State Ion. 32/33 198.

[90] Je'ze'quel, D.; Guenot, J.; Jouini, N.; Fie'vet, F. J. Mater. Res. 1995,10, 77.

[91] Joseyphus, R. J.; Kodama, D.; Matsumoto, T.; Sato, Y.; Jeyadevan, B.; Tohji, K. J. Magn. Magn. Mater. 2007, 310 (2), 2393.

[92] Hong-Ling Liua, Seung Pil Kob, Jun-Hua Wuc,, Myung-Hwa Jungd, Ji Hyun Minb, Ju Hun Leeb, Boo Hyun Anb, Young Keun Kimb, Journal of Magnetism and Magnetic Materials 310 (2007) 815-817

[93] B.D. Cullity, S.R. Stock, in: Elements of X-ray Diffraction, Prentice Hall, Englewood Cliffs, New Jersey, 2001.

[94] S. Sun, H. Zeng, J. Am. Chem. Soc. 124 (2002) 8204.

[95] S. Si, A. Kotal, T.K. Mandal, S. Giri, H. Nakamura, T. Kohara,Chem. Mater. 16 (2004) 3489.

[96] A. Tavakoli, M. Sohrabi, A. Kargari, Chemical Papers 61 (3) 
(2007) 151-170.

[97] Y.L. Hao, A.S. Teja, Journal of Materials Research 18 (2) (2003) 415-422.

[98] C. Xu, A.S. Teja, Journal of Supercritical Fluids 44 (1) (2008) 85-91.

[99] C. Xu, J. Lee, A.S. Teja, Journal of Supercritical Fluids 44 (1) (2008) 92-97.

[100] Osuna, J.; de Caro, D.; Amiens, C.; Chaudret, B.; Snoeck, E.; Respaud, M.; Broto, J. M.; Fert, A. J. Phys. Chem. 1996, 10.

[101] Park, S. J.; Kim, S.; Lee, S.; Khim, Z. G.; Char, K.; Hyeon, T. J. Am. Chem. Soc. 2000, 122, 8581.

[102] Amir Hassanjani-Roshan, Mohammad Reza Vaezi, Ali Shokuhfarc, Zohreh Rajabali. Particuology 9 (2011) 95-99.

[103] Ashok kumar, M., Lee, J., Kentish, S., \& Grieser, F. (2007). Bubbles in an acoustic field: An overview. Ultrasonics Sonochemistry, $14,470-475$.

[104] Suslick, K. S. (1998). Sonochemistry, in Kirk-Othmer encyclopedia of chemical technology (4th ed.) John Wiley \& Sons: New York. , pp. 517-541.

[105] Wang, X. K., Chen, G. H., \& Guo, W. L. (2003). Sono- chemical degradation of kinetics of methyl violet in aqueous solutions. Molecules, 8, 40-44.

[106] Mason, T. J., \& Lorimer, J. P. (2002). Applied sonochemistry: Uses of power ultrasound in chemistry and processing. Weinheim:Wiley-VCH.

[107] Suslick, K. S., Didenko, Y., Fang, M. M., Hyeon, T., Kolbeck, K. J., McNamara, W. B., III, et al. (1999).Acoustic cavitation and its chemical consequences. Philosophical Transactions of the Royal Society A, 357, 335-353.

[108] Jiri Pinkas , Vendula Reichlova, Radek Zboril , Zdenek Moravec ,Petr Bezdicka c, Jirina Matejkova .Ultrasonics Sonochemistry 15 (2008) 257-264.

[109] R. Gedye, F. Smith, K. Westaway, H. Ali, L. Baldisera, L. Laberge, J. Rousell, Tetrahedron Lett. 27 (1986) 279.

[110] R.J. Giguere, T.L. Bray, S.M. Duncan, G. Majetich, Tetrahedron Lett. 27 (1986) 4945.

[111] Norihito Kijima, Masashi Yoshinaga, Junji Awaka, Junji Akimoto. Solid State Ionics (2011) (Article in press).

[112] J.G. Parsons, C. Luna, C.E. Botez, J. Elizalde, J.L. Gardea-Torresdey. Journal of Physics and Chemistry of Solids 70 (2009) 555-560. 